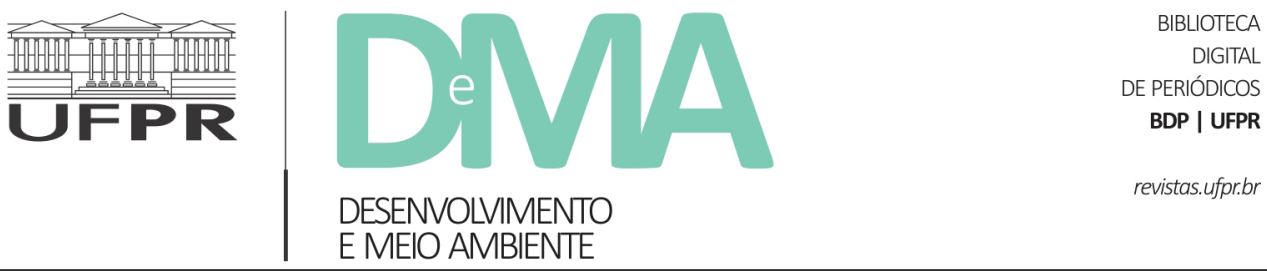

\title{
Turismo de base comunitária: uma perspectiva desde o bem viver como alternativa ao desenvolvimento na América Latina e Abya Yala
}

\section{Community-based tourism: the good living perspective as an alternative to development in Latin America and the Abya Yala}

\author{
Rodrigo Cuevas VARGAS ${ }^{1}$, Christian Henríquez ZUÑIGA², Liliane Cristine Schlemer ALCANTARA ${ }^{3,4 *}$ \\ ${ }^{1}$ Centro Transdisciplinario de Estudios Ambientales, Universidad Austral de Chile (UACh), Valdivia, Chile. \\ ${ }^{2}$ Facultad de Ciencias Socias y Económicas, Universidade Católica del Maule, Talca, Chile. \\ ${ }^{3}$ Faculdade de Administração e Ciências Contábeis, Universidade Federal de Mato Grosso (UFMT), Cuiabá, Mato Grosso, Brasil \\ ${ }^{4}$ Programa de Pós-graduação em Ciências Ambientais, Universidade do Estado de Mato Grosso (UNEMAT), Cáceres, Mato Grosso, Brasil. \\ *E-mail de contato: lilianecsa@yahoo.com.br
}

Artigo recebido em 28 de agosto de 2019, versão final aceita em 18 de abril de 2020, publicado em 2 de setembro de 2020.

RESUMO: O Bem Viver como conceito ontológico proveniente do mundo dos povos originais, vem sendo a partir de seu reconhecimento em diversas esferas e níveis teóricos, políticos e incluso empresariais, um campo em disputa, sendo em alguns casos, esvaziado e apropriado de seu conteúdo cultural e de sua função emancipadora. Por sua parte, o Turismo de Base Comunitária (TBC) se apresenta como uma das possibilidades práticas de repensar e prospectar um desenvolvimento fundado em uma articulação orgânica entre humanos e entre humano e não humanos, resgatando e atualizando o sentido de comunidade em harmonia com a natureza. Metodologicamente, utilizou-se de revisão teórica com análise crítica e estudo de caso do Programa de TBC em Trawun de Panguipulli, Sul do Chile. Por meio de uma discussão/reflexão entre estes conceitos buscouse discutir elementos que se aproximam ou se distanciam entre os temas a fim de contribuir neste propósito. O objetivo do artigo é dialogar sobre o tema de Turismo de Base Comunitária como estratégia alternativa e emancipadora de desenvolvimento, desde a perspectiva do Bem Viver. Concluiu-se que pensar em novos paradigmas sustentados em perspectivas ontológicas, supõe também enfrentar o desafio de propor projetos que possam disputar as lógicas de apropriação e em tempo, fortaleçam e reafirmem os territórios e as identidades territoriais das comunidades rurais, campesinas e dos povos originários.

Palavras-chave: diálogos; bem viver; turismo de base comunitária; estratégias; alternativas ao desenvolvimento.

Desenvolv. e Meio Ambiente usa uma Licença Creative Commons - Atribuição-NãoComercial-SemDerivações 4.0 Internacional 
ABSTRACT: The Good Living as an ontological concept, comes from the world of the original peoples and has been from its recognition in various spheres and theoretical levels, political and even business, a field in dispute, being in some cases emptied and appropriate of its cultural content and its emancipatory function. For its part, Community-Based Tourism (CBT) presents itself as one of the practical possibilities of rethinking and prospecting a development based on an organic articulation between humans and between humans and nonhumans, rescuing and updating the sense of community in harmony with nature. Methodologically, we used a theoretical review with critical analysis and case study of the CBT Program in Trawun de Panguipulli, southern Chile. Through a discussion / reflection, between these concepts we sought to discuss elements that approach or distance themselves between the topics in order to contribute to this purpose. The objective of this article is to dialogue on the theme of Community Based Tourism as an alternative and emancipatory strategy of development from the perpective of Good Living. It was concluded that, thinking about new paradigms based on ontological perspectives, also supposes facing the challenge of proposing projects that can dispute the logic of appropriation and in time, strengthen and reaffirm the territories and territorial identities of, rural communities, peasants and native peoples.

Keywords: dialogues; good living; community-based tourism; strategies; alternatives to development.

\section{Introdução}

Neste artigo procurou-se identificar as aproximações e distanciamentos entre dois conceitos que se encontram atualmente em árdua discussão, construção e definição a escala latino-americana: de um lado, o tema do Bem Viver e, de outro, o tema do Turismo de Base Comunitária (TBC). Apesar da relação dialética entre os temas, faz-se necessário aprofundar o discurso de ambos conceitos desde sua epistemologia, princípios e objetivos.

O Equador e a Bolívia são os países onde existe uma maior trajetória do Bem Viver, assim como um campo melhor definido para seu estudo. Destacam-se a Constituição do Equador de 2008 e o Plan Nacional Estratégico del Buen Vivir de 2009-2013/2013-2017/2017-2021. Suas diretrizes giram em torno do valor da biodiversidade e da conservação dos modos de vida, como base jurídica para pensar políticas de desenvolvimento (Cabanilla, 2014). De outro lado, a Bolívia se destaca pela
Constituição de 2009 e pelo Plan del Desarrollo Económico y Social do marco de desenvolvimento do Vivir Bien.

Se bem que é necessário e fundamental que exista uma maior compreensão e visibilidade do tema Bem Viver e se outorgue a ele reconhecimento sob um marco de atuação legal traduzido em políticas públicas, se reconhece a crescente multiplicidade de interpretações e as disputas e apropriações disciplinarias dadas ao significado original. Neste sentido, é preciso não esquecer que o Bem Viver é uma conquista dos movimentos sociais e das comunidades dos povos originais andinos a fim de promover outras formas e alternativas ao desenvolvimento.

A tradução do seu real sentido, muitas vezes leva a um vazio de entendimento, uma deturpação, pois como objeto de apropriação conceitual por parte de grupos políticos, econômicos e intelectuais com interesses totalmente opostos, muda o sentido originalmente proposto. Para Dagnino (2004), este 
fenômeno gera uma confluência perversa e uma crise discursiva, produto de uma relação de sentidos que se estabelecem conceitualmente frente a um campo adversário. Neste caso, dado pelo avanço do modelo neoliberal representado por grandes corporações transnacionais respaldadas pelo Estado, onde os territórios rurais e grandes reservas de recursos naturais se apresentam como campo de disputa ${ }^{1}$.

De outro lado, o Turismo de Base Comunitária (TBC) pode ser entendido como uma estratégia de desenvolvimento no qual a comunidade é protagonista no processo de produção da oferta turística (Sampaio, 2005; Henríquez, 2007; Zechner et al., 2008). Neste sentido, duas perspectivas são evidentes nessa concepção de TBC: a primeira considera o TBC como um modo de desenvolvimento da atividade turística, pensando em processos, etapas e técnicas de implementação, tendo uma conotação prescritiva, e na qual o TBC pode ser entendido como mais um tipo ou modelo de turismo; a segunda, se fundamenta no protagonismo comunitário, ou seja, requer pensar o TBC como um meio para empoderar comunidades tradicionais.

Neste caso, tanto o TBC como o Bem Viver, possuem um especial interesse nas comunidades endógenas, desmascarando "boas práticas" e/ou formas dominantes de exploração extrativista dos territórios. Portanto, o objetivo principal está em dialogar sobre o Turismo de Base Comunitária como proposta alternativa e teórico-prática ao desenvolvimento desde a perspectiva do Bem Viver. Considerando a análise de ambos campos por meio de um aprofundamento de suas bases teóricas, meto- dologicamente está sustentado numa revisão teórica com análise crítica. Neste sentido, procurou-se a busca de reflexões que possam a partir de um estudo de caso, trazer bases para uma leitura endêmica dos territórios. Assim, buscou-se em práticas, princípios e ferramentas, um modelo que possa desta forma resguardá-los frente ao modelo antropocêntrico e hegemônico que se pretende combater. Esta proposta sem dúvida, não nega a condição permanente de sua construção conceitual, sendo o presente artigo uma contribuição para fortalecer o caminho epistemológico e transdisciplinar que se pretende apresentar.

O texto centra-se na trajetória, ideias e práticas que alimentam ambos os campos teóricos, bem como sua inscrição em corpos teóricos maiores como a Economia Social e Solidária de Coraggio (2013), os estudos decoloniais de Walsh (2005; 2017), as alternativas ao desenvolvimento de Gudynas \& Acosta (2011) e de Alcântara \& Sampaio (2017); a perspectiva do Desenvolvimento a Escala Humana de Max-Neef et al. (1993) e da Economia Desenmascarada de Max-Neef (2014), e de TBC de Sampaio (2005), Sampaio et al. (2011), Henríquez (2007) e Henríquez et al. (2010).

O desafio está em discutir elementos que se aproximam ou se distanciam entre os temas e, ao mesmo tempo, identificar perspectivas futuras que possam propor novos caminhos e formas de vida frente ao avanço do neoliberalismo extrativista da região em questão. Deste modo, analisou-se o programa de Turismo de Base Comunitária Trawun², no municipio de Panguipulli, sul do Chile, como

\footnotetext{
${ }^{1}$ Dagnino (2004) utiliza o conceito de confluência perversa a partir da disputa de significado de democracia e participação cidadã no processo sociopolítico brasileiro dos anos 90. Porém é pertinente no atual momento de debate em torno do Bem Viver e do Turismo Comunitário.

2 "Encontro" em mapuzungún, idioma do povo Mapuche.
} 
exemplo contemporâneo de proposta de TBC com foco no Bem Viver (Henríquez \& Pacheco, 2017).

\section{Novas perspectivas: a necessidade de aproximações conceituais}

A racionalidade do pensamento binário e instrumental moderno é como um fantasma que se manifesta cada vez que um projeto alternativo avança na busca e realização de um imaginário social pós-capitalista. Para Svampa (2016), os governos da chamada esquerda progressista que surgiram com força no começo do século XXI na América Latina, buscam escapar a este estereótipo que hoje se encontra no fim de seu ciclo. Entretanto, este modelo deixou como consequência um capitalismo que se tornou ainda mais forte, em consonância com a fase "desemascarada" do modelo neoliberal que se experimenta a escala global/ocidental (Max-Neef \& Smith, 2014).

O deslocamento do Bem Viver desde os territórios dos povos originários até as esferas políticas, no que Vanhults (2015) define como corrente socialista $^{3}$, provocou um vazio de seu conteúdo e uma apropriação dele por parte do Estado. Ou seja, uma confluência perversa que em nome do Bem Viver justificou a exploração exacerbada dos recursos naturais por meio da economia extrativista, sustentada no consenso dos commodities (Svampa, 2011), resultando em forte tensões e conflitos com as comunidades indígenas e rurais na América Latina ${ }^{4}$.
A tensão atual dos conflitos socioterritoriais por uso e apropriação de natureza em escala latino-americana, assinala que os caminhos tomados tanto pelos chamados governos de esquerda progressista, como os de corte liberal, coincidem em sua visão linear de progresso e desenvolvimento baseado na perspectiva racional de consumo e acumulação de bens (Svampa, 2011; 2016; Solón, 2016). Deste modo, faz-se necessário refazer caminhos, estratégias epistêmicas e políticas que contribuam para superar a atual crise civilizatória (Santos, 2010), ou aquilo que Zibechi (2016) reconhece como um colapso sistêmico, sinalizando que a complexidade e extensão do sistema neoliberal frente a um colapso não abririam "zonas de refúgio". Por isso a emergência de um paradigma alternativo. Santos (2010, p. 17) assinala que esta reformulação somente será possível aproximando o pensamento ocidental com o pensamento "[...] que emerge desde outros sentidos, onde a dignidade, o respeito, o território, o autogoverno, o Bem Viver e a Mãe Terra se constituam como novas epistemes que vão mais além dos tradicionais conceitos [...] direitos humanos, democracia e desenvolvimento". Deste modo, o verdadeiro sentido do Bem Viver necessitaria ser recuperado com o objetivo de constituir-se como uma alternativa real.

Tal recuperação se daria - entre outras coisas - por meio do reconhecimento do espaço geográfico e do território que sustenta as epistemes ontológicas (Souza, 2007; Porto-Gonçalves, 2009), como é o caso do Sumak Kawsay (Quechua), Suma Qamaña

\footnotetext{
${ }^{3} \mathrm{O}$ autor diferencia três correntes do Bom Viver, a dizer: a corrente indigenista, que provém dos povos originários; a socialista ou progressista, que provem dos governos progressistas; e a pós-estruturalista, ligada aos debates acadêmicos (Vanhults, 2015).

${ }^{4}$ Em 2016 a América Latina teve o mais alto índice de assassinatos de líderes e ativistas ambientais, com $60 \%$ do total de 200 contabilizados em nível global. Durante o ano de 2017, a América Latina manteve o ranking de assassinatos, onde a agroindústria e a mineração se constituem como os maiores negócios vinculados ao assassinato de líderes indígenas, campesinos e ativistas (Global Witness 2016; 2017).
} 
(Aymara) ou o Kume Mongen (Mapuche). A partir daqui, a proposta de desenvolvimento alternativo deveria considerar o fortalecimento dos territórios, e reconhecimento de outras formas de ser e estar no mundo, como formas de vida que sempre existiram, sobreviveram e preservaram suas características com um certo grau de autonomia frente ao processo de modernização e colonização. Para Max-Neef et al. (1993) é uma articulação orgânica entre o ser humano com a natureza e a tecnologia que se apresenta como terceiro pilar do desenvolvimento à escala humana.

\section{Contexto latino-americano: trajetória do Bem Viver e do Turismo de Base Comunitária}

A primeira ruptura das formas de vida tradicional da América Latina e da Abya Yala ${ }^{5}$ com o pensamento ocidental/colonial - caracterizado este último pelo alto grau de individualismo, entre outras coisas - provém do sistema comunitário que se constitui como pilar fundamental das práticas de construção social dos povos originários (Macas, 2014), tendo como reconhecimento outras formas vida em harmonia com a natureza e o universo: a Pachamama como um todo, entendida não somente como a Mãe Terra, mas também como uma unidade indissociável do espaço-tempo (Solón, 2016). Nesta perspectiva cíclica e espiral, se ultrapassa a forma linear que caracteriza o pensamento ocidental-instrumental, por meio de uma compreensão do mundo além da racionalidade econômica, complexa e simples ao mesmo tempo. Para Sampaio et al. (2017), o Bem Viver relaciona-se com condicionantes éticos e emancipação humana, ou seja, com a dinâmica social, mas ao mesmo tempo conectado ao meio no qual se vive, isto é: a dinâmica ambiental.

$\mathrm{O}$ pensamento crítico latino-americano se encontra atualmente em uma reconfiguração até novos campos, tanto epistêmicos como sociais de compreensão e formulação conjunta de um projeto emancipador, que dialogam entre si por meio das vertentes de Escobar (2016), que distinguem o "pensamento autônomo" ou "desde abaixo", e o "pensamento da Terra". O primeiro entende-se por um projeto surgido desde a reivindicação de territórios autônomos que tem a comunidade como pilar fundamental, tal como o Zapatismo (México) e o Movimento dos Sem Terra-MST (Brasil); e o segundo pensamento, é aquele cuja dimensão estaria associada às lutas territoriais pela defesa da terra, $\mathrm{e}$ que expressa a cultura, práticas sociais, artísticas e econômicas das comunidades e povos que habitam diversos territórios, principalmente comunidades originárias.

Neste sentido, apesar da literatura descrever os temas Sumak Kawsay e Bem Viver como sinônimos, ambos derivam de diferentes lógicas civilizatórias e de diferentes línguas (Acosta, 2015). O Bem Viver poderia se inscrever como um pensamento da terra, sustentado nas grandes discussões teóricas no marco do que conhecemos como corrente decolonial. Para Walsh (2017), não existe um estado nulo da colonialidade, senão posturas, posicionamentos, horizontes

\footnotetext{
${ }^{5}$ O Abya Yala é o nome que o povo Kuna, localizados ao sul do Panamá e norte de Colômbia, dava ao continente "rodeado de mar", "terra matura", "terra viva" ou "terra em florescimento" (Mardones \& Fernández, 2016). Vem surgindo com força na esfera política a partir do "Foro Indígena de Abya Yala" realizado em 2013, onde representantes indígenas de 17 países do continente participarem da "Conferência Mundial sobre povos indígenas", organizado pela ONU e realizado na Guatemala, no ano 2014 (Del Popolo, 2017).
} 
e projetos de resistir, transgredir, intervir, insurgir, crer e incidir. O decolonial denota, então, “[...] um caminho de luta contínuo no qual se pode identificar, visibilizar e encorajar 'lugares' de exterioridade e construções alternativas" (p. 25). Esta nova forma de explicar o mundo além dos limites da racionalidade moderna, que inclui o sentir, a espiritualidade, a emoção, ao mesmo tempo em que se reproduz o território como espaço autônomo e comunitário, abrindo espaço para uma nova "ontologia materialista” (Escobar, 2016).

Por tanto, o Bem Viver como conceito situado e surgido nos territórios dos povos originários, se constitui como um campo epistêmico, ontológico e prático, que possibilita o encontro de múltiplas culturas, surgidas desde as margens do poder, desde a dimensão material do território como suporte da reprodução de formas de vida, assim como a dimensão da territorialidade das práticas que lhe dão sentido.

O debate sobre a crise de caráter sistêmico e civilizatório sugere reflexão sobre o sentido de Bem Viver, o qual se relaciona a qualidade de vida e remete a questões como espiritualidade, natureza, modos de vida, consumo, política e ética. Nessa perspectiva, há necessidade de amadurecer o diá- logo sobre o tema Bem Viver como uma proposta alternativa de desenvolvimento, quando se pensa a relação sociedade e natureza (Alcântara \& Sampaio, 2017, p. 233).

A partir da chegada e consolidação dos governos progressistas do Equador com o Bem Viver (Buen Vivir), e da Bolívia com o Viver Bem (Vivir Bien) em suas respectivas constituições e planos de desenvolvimento, foram impulsionados projetos econômicos extrativistas que investem paradoxalmente contra as reservas naturais e os povos originários que nelas habitam. Exemplos disso, são os casos emblemáticos dos projetos de Yasuni-ITT na Amazônia Equatoriana ${ }^{6}$ e a estrada que atravessaria o TIPNIS da Bolívia ${ }^{7}$. Apesar de citar estes dois países pelo paradoxo e contradição que representam ao outorgar valor jurídico ao Buen Vivir/Vivir Bien ao mesmo tempo em que impulsam projetos extrativistas; este modelo vem operando na totalidade dos países da Abya Yala, onde os conflitos com comunidades indígenas e campesinas vem se agravando transversalmente nos últimos anos.

A chamada Iniciativa para Integração da Infraestrutura Regional Sul-Americana (IIRSA), que vem operando como plano de desenvolvimento desde o começo do século XXI, nos 12 países da

\footnotetext{
${ }^{6}$ A iniciativa Yasuní-ITT (referência a três zonas de extração petroleira: Ishpingo-Tambococha-Tiputini, no parque nacional Yasuni, no Equador) se apresentou como uma proposta revolucionária ao nível internacional em matéria de mudança climática e mudança da matriz energética global. Tratava-se de solicitar a comunidade internacional e países mais ricos do mundo - por meio da co-responsabilidade ambiental e a dívida climática - uma contribuição do $50 \%$ dos ganhos obtidas se essas reservas de petróleo fossem exploradas, para investir o dinheiro na mudança da matriz energética do país. Procurava-se evitar a geração de 410 milhões de toneladas de dióxido de carbono (CO2), favorecer a conservação da biodiversidade da Amazônia, evitar a deflorestação e respeitar os direitos dos povos originários que moram no Parque reconhecido pela UNESCO. Devido a pouca arrecadação de dinheiro, o presidente Rafael Correa deu fim a iniciativa Yasuní-ITT no 2013, começando assim a exploração de petróleo, isto gerou a manifestação da população do pais, pois justamente começava a contradizer a constituição que garantia a defesa dos povos originários e propunha o Bem Viver (Le Quang, 2015).

${ }^{7}$ O presidente Evo Morales decide no 2011 construir a estrada Villa Tunari-San Ignacio de Mojos, atravessando o Território Indígena Parque Nacional Isiboro-Sécure (TIPNIS) na Bolívia, que resultou na "VIII Marcha de Indígenas de Tierras Bajas” (Tamburini, 2018).
} 
região sul-americana, perpassa qualquer viés político-governamental. Em palavras de Quental (2013), corresponde a um projeto de integração regional "compreendida como sinônimo de liberalização comercial" (p. 5), no qual a interconexão física do continente insere-se "como estratégia de resposta às novas e crescentes demandas asiáticas por commoditties" (p. 3). Aliás, o projeto TIPNIS na Bolívia faz parte dessa ideia e plano de desenvolvimento, voltando a se perpetuar o desenvolvimento de exploração de recursos sob um domínio da natureza.

Refletindo nas contradições surgidas no seio dos governos progressistas, em uma leitura destes fenômenos ocorridos, observa-se uma apropriação da energia dos próprios movimentos sociais e comunidades que ajudaram a nutrir e levantar os projetos políticos partidários que foram perdendo autonomia e capacidade crítica frente aos novos governos (Sólon, 2016; Svampa, 2016). A questão crucial é como se pode chegar a uma relação entre os projetos políticos que operam em escala de Estado e as políticas de desenvolvimento com a diversidade de territórios e comunidades rurais do interior, que apostam pelo reconhecimento e fortalecimento de suas formas de vida desde a autonomia e autogestão.

Parece que a busca por compreender outras formas de relação do homem com seu território, natureza, sociedade entendida como comunidade e espiritualidade, muitas vezes se quebra ou se perde no momento que se transita desde o território até as estruturas de poder (Cuevas, 2017), tal como se percebe nos projetos e políticas de desenvolvimento no Equador, Bolívia e na totalidade da América-latina. Isto é provavelmente, uma das principais causas pelas quais o Bem Viver tem sido esvaziado de seu sentido ontológico na trajetória dos governos progressistas. Ou seja, desde os povos originários até o uso e apropriação do discurso pelas esferas institucionais e políticas de Estado. Claramente este efeito provoca um problema de suporte no imaginário conceitual, pois o território como categoria geográfica definida e limitada pela reprodução sociocultural das comunidades é inerente à definição de Bem Viver, mas perde seus limites e, portanto, a ancoragem que garante seu ciclo e sua reprodução sociocultural (Porto-Gonçalves, 2009; Cuevas, 2017).

Teorias anteriores ao conceito de Bem Viver como Desenvolvimento à Escala Humana e a economia ecológica (Max-Neef et al., 1993), abrem espaços para se pensar em quanta natureza dispomos e quanto usaremos para sustentar os estilos de vida atuais ${ }^{8}$. Assim, estabelecem-se limites planetários sob o princípio de finitude e postula-se que a economia é um subsistema de um sistema maior e finito que é a biosfera e, portanto, o crescimento permanente é impossível (Max-Neef, 2017; Henríquez, 2009). Nesta relação, e inspirado em outras economias, o Turismo de Base Comunitária (TBC) surge não apenas como uma nova modalidade turística $\mathrm{e}$ proposta alternativa, senão como uma tentativa de iniciar um diálogo e conciliar uma maneira distinta de pensar e organizar o turismo, um eixo capaz de configurar sócio-espacialmente os territórios no

\footnotetext{
${ }^{8}$ A visão dominante de que os recursos naturais são infinitos e que por tanto o crescimento é exponencial deve chegar ao seu fim. Informes da condição ambiental atual do planeta são as principais fontes cientificas que ajuda a quebrar essa ideia, tais como os relatórios do "Planeta Vivo" da WWF International (WWF, 2018).
} 
paradigma do desenvolvimento endógeno (Coriolano, 2016). Igual aos diversos conceitos discutidos, o TBC como fenômeno recente se encontra em um atual e fértil debate que busca situá-lo como alternativa ao desenvolvimento possível, surgida desde os contextos rurais, campesinos e dos povos originários.

Em sua definição, o TBC se distancia da visão clássica do turismo convencional que mercantiliza as paisagens e comunidades tradicionais, para ao contrário, abrir possibilidades de diálogo entre os diferentes modos de vida comunitários. No caso entre visitantes e visitados, em um diálogo que envolve comunidade, convivencialidade e cotidianidade (Henríquez et al., 2010; Marín-Herrera, 2015; Marín-Herrera \& Henríquez, 2015). Entre seus principais pressupostos estão: os vínculos de identidade e confiança construídos na comunidade; a relação entre a comunidade e os diferentes modos de vida; e o cotidiano como prática de reprodução da vida com suas características e costumes (Skewes et al., 2012). O TBC, responde assim a um desafio do século XXI (Henríquez, 2014), de promover modos de vida tradicionais na recuperação de suas particularidades, que se apresentam ambientalmente mais sustentáveis, reconhecendo suas dinâmicas particulares, ao mesmo tempo que dialogam com o mundo moderno, o desenvolvimento e a economia de mercado (Sampaio, 2005; Sampaio, 2010); estabelecendo, portanto, a necessária relação de confluência conceitual entre o mundo comunitário e o mundo do Estado, que hoje é dominado pelo mercado.

Assim, observamos que a relação dialética que propõe o TBC entre territórios autônomos por um lado e políticas que promovem seu desenvolvimento por outro, reconhece ainda variáveis da Economia
Social e Solidária estudadas por Coraggio (2013). Sua inscrição poderia se dar dentro da "economia mista" (compreendendo relação dada pelos sectores econômicos de: empresa privada, Estado, e economia popular), onde se reconhece e trabalha em conjunto com órgãos público institucionais e privados; ao mesmo tempo em que é promovida a criação de sistemas orgânicos que incluem produção, distribuição, circulação, comercialização e consumo por meio de associações campesinas ou indígenas. Assim, podem se oferecer no mercado experiências solidárias ligadas à hospedagem, gastronomia, cultura, visitas de campo, artesanato, por exemplo; formando, além disso, redes de atores e sujeitos que atuam em conjunto frente às variáveis externas que se apresentam (Coraggio, 2013). Também o TBC contém um alto grau de relação com a corrente proposta como "Outra Economia", que tem em sua definição a busca de superação do sistema econômico, que implica [...] não somente diferenciar-se e separar-se senão se propor como forma superior as práticas próprias do capital, disputando o sentido de critérios, práticas, propostas em nível micro e mesoeconômico, em uma luta onde a economia, política e cultura se veem fortemente imbricadas (Coraggio, 2013, p. 21).

A relação do TBC como proposta que busca reverter a subordinação das economias populares e públicas dentro de um quadro dominado principalmente pelo Capital privado, faz com que se deva nutrir fortemente, pois é justamente neste marco de relacionamento desigual, que se torna plausível de ser esvaziado de seu significado pelo domínio do capital.

Nesse delicado ponto, a perspectiva das ecossocioeconomias (Sampaio, 2010) permite compreender as práticas turísticas alternativas sendo carre- 
gadas de um componente inovador, questionando as teorias pré-existentes, que podem reunir requisitos do paradigma decadente para que se realize a transitoriedade entre o velho e o novo contexto. $\mathrm{O}$ que pode parecer contradição, corrobora com Thomas Kuhn (1970) e, posteriormente, com Enrique Leff (2001), quando estes sugerem que a passagem para racionalidade ambiental perpassa pela racionalidade econômica. Neste sentido, toma-se a precaução de não reverenciar as ecossocioeconomias como que essas pudessem ser respostas aos problemas contemporâneos ou, ainda, como que essas fossem consideradas uma forma hegemônica de alternativa de vida.

Neste contexto, problematiza-se o Turismo de Base Comunitária (TBC), no qual pode ser compreendido como experiências que concebem o desenvolvimento por quem vive no território e que possuem uma dinâmica sinérgica entre seu patrimônio cultural e natural, o que as tornam instrumentalmente e turisticamente atrativas, no entanto substancialmente como práticas pedagógicas para repensar modos de vida, produção e conhecimento.

Como implicações diretas do TBC destacam-se o fortalecimento e recuperação dos territórios, resgate de práticas identitárias e simbólicas, geração de ingressos complementários em comunidades; bem como oportunidades de trabalho intergeneracional para mulheres e jovens, como principais impulsionadoras destas iniciativas. Assim também surge o fortalecimento do associativismo e a recuperação de práticas econômicas comunitárias; e por último, a conservação, proteção e defesa do território e de seus recursos frente às ameaças dos interesses capitalistas (Pilquiman \& Henríquez, 2017). Começamos a enxergar assim, como o TBC pode partir da consolidação das comunidades, ge- rar uma economia que como intenta definir Ortiz (2012), deve entender que há uma ponte desde uma ética até uma espiritualidade de desenvolvimento; e que é justamente o que o mundo dos povos originários nos apresentam, podendo se traduzir também, nas ideias do sentir-pensar com a Terra (Escobar, 2016). Ante o exposto, percebe-se que o TBC pode constituir-se numa estratégia de resistência, ao mesmo tempo em que disputa espaços de poder e estrutura institucional em níveis crescentes de autodependência dos territórios e formas de vida que ali se reproduzem. Nesta disputa, se percebe a relação na busca de novos paradigmas de desenvolvimento alternativo, como o Bem Viver.

\section{Desafios a partir do diálogo emancipador}

O espaço geográfico de onde surge, visualiza e se sustenta tanto o Bem Viver como o Turismo de Base Comunitária, se encontra no território habitado por povos originários e rurais tradicionais como campesinos e agricultores. Isto nos permite vislumbrar que estas comunidades possuem aproximações que situam-se em ambos os conceitos desde o mesmo ponto, reconhecendo, porém, sua diversidade histórica e cultural dos contextos geográficos rurais da região e de sua pluridiversidade, bem como na relação e na forma de como se concebem e se expressam no cotidiano.

Se por um lado, o Bem Viver se inscreve como um conceito ontológico (Cuevas \& Henríquez, 2017), referente as formas de vida e reprodução social dos povos originários em harmonia com os ciclos da terra e o reconhecimento da Mãe Terra; por outro lado, o Turismo de Base Comunitário pode encontrar nos campos da Economia Social e 
Solidária, uma forma de gerar ingressos a partir de experiências materiais e imateriais, paisagísticas, culturais e simbólicas existentes nas comunidades visitadas.

O desafio que se vislumbra a partir da aproximação destes campos conceituais permite enxergar caminhos que parecem entrelaçados. Primeiramente, desde uma perspectiva do marco teórico para construir permanentemente o paradigma alternativo de desenvolvimento sustentado tanto no Bem Viver como no Turismo de Base Comunitária; escapando assim dos essencialismos para constituir-se desde conceitos de relacionalidade (Gudynas \& Acosta, 2011), até a pluridiversidade e a interculturalidade, entendendo-os como: "processos de intercâmbio que permitam construir espaços de encontro entre seres e saberes, sentidos e práticas distintas" (Walsh, 2005, p. 45).

Em segundo, deve se considerar as diferentes escalas de aplicação e estruturação do caminho de materialização que leva a práxis. Isto quer dizer em outras palavras, suas estratégias políticas e econômicas em relação as suas dimensões de microeconomia (Coraggio, 2013), valorizando a economia do trabalho solidário à escala familiar e comunitária. Tanto em nível local, promovendo articulações ecológicas e solidárias entre setores e atores (comunidades e povos), destacando "o comunitário, desde o território"; como, em nível nacional, envolvendo todos os atores econômicos, "[...] desde o empoderamento dos povos indígenas e campesinos, incluindo as empresas privadas e o Estado em suas potencialidades de ações de responsabilidade e solidariedade" (Ortiz, 2012, p. 96).

\section{Programa Trawun em zona de educação para uma outra economia}

Para problematizar este cenário e como uma tentativa de aproximação na práxis destes conceitos, pode-se mencionar o caso do Parque Nacional Villarrica, situado na XIV Región de los Ríos, sul de Chile. Território ancestral mapuche chamado por eles de Rukapillán e Peweñantu ${ }^{9}$, contém uma alta carga simbólica e espiritual, sendo hoje negado como espaço mapuche de reprodução socioterritorial, cultural, econômico e espiritual (Marín-Herrera \& Henríquez, 2015) pelo Estado de Chile. Se encontra em uma disputa com o Estado chileno pelo controle territorial desde sua criação em 1940, quando às comunidades que o habitam, transitam e fazem uso ancestral de seu espaço são deslocadas e privadas dele, gerando múltiplas pobrezas (Marín-Herrera \& Henríquez, 2015; Fernández-Comino, 2018). Entendidas também como carências de possibilidades de satisfazer adequadamente as necessidades humanas fundamentais, que possibilitam níveis crescentes de autodependência (Max-Neef et al., 2011), gerando consequências graves, como a perda da racionalidade e o conhecimento tradicional das comunidades, substituído pelo conhecimento científico do Estado como novo administrador de seu território (Marín-Herrera \& Henríquez, 2015).

Esta indefinição sobre a propriedade, demandou reivindicações dos povos originários, associado à demanda mundial pela preservação de zonas naturais de um lado; e de outro, pelo Estado e instituições particulares, em utilizar seus recursos como atrativos turísticos e desenvolvimento econômico ${ }^{10}$.

\footnotetext{
${ }^{9}$ Rukapillán e o nome mapuche do Vulcano Villarica e Peweñantu é o nome de uma área em volta do Rukapillán onde se encontram a araucárias.
}

${ }^{10}$ De fato, a atual disputa da zona tem a ver com o desenvolvimento e criação de um centro de esqui. O governo projetou uma estrada que 
Deste modo, surge a necessidade de reapropriação dos territórios e de sua decolonização deste espaço pelas comunidades originárias (Marín-Herrera \& Henríquez, 2015), ao tempo em que são denunciados os sentidos que operam por trás das políticas de desenvolvimento dominante ${ }^{11}$.

Este é um cenário em que o Turismo de Base Comunitária vem se apresentando como uma das ferramentas que as comunidades podem utilizar para defender seus territórios de ameaças socioambientais, socioculturais, sociopolíticas, socioeconômicas e socioespaciais (Henríquez et al., 2010); impulsando iniciativas conjuntas em nível comunitário e familiar, para promover atividades turísticas que gerem tanto benefícios econômicos para os grupos locais, como reconhecimento e valor por parte dos visitantes até outras formas de existir e re-existir no mundo (Marín-Herrera, 2015). Este processo representa uma forma de resistência, manutenção de sua cultura e dentro do contexto de alternativas ao desenvolvimento. As comunidades mapuche do Parque Nacional Villarrica, vem construindo projetos de recuperação territorial, que passam por diferentes âmbitos:

[...] A definição de acordos informais com a administração do parque para fazer uso da sua diversidade a partir de práticas tradicionais como a piñonada; a recuperação da toponímia (nomes próprios dos lugares do território); os projetos de Turismo Comunitário que procuram o respeito pelos modos de vida das comunidades tradicionais junto à preservação da natureza (Marín-Herrera \& Henríquez, 2015, p. 23).
Neste contexto, surge e se apresenta no ano 2013 o programa TRAWUN ${ }^{12}$ que propõe por meio de metodologias de incubação territorial um Programa de Turismo de Base Comunitária, Economia Solidária e Desenvolvimento de Base Local, cujo objetivo é "[...] trabalhar em um prazo de dez anos, tentando gerar sinergias entre distintos projetos que formem parte de uma planificação com um olhar mais amplo do turismo, desenvolvimento e economia" (Fernandez \& Henríquez, 2018). O programa define o TBC desde um enfoque dirigido na busca de novas experiências:

[...] já que não se trata de buscar novas paisagens senão "re-aprender" a olhar os detalhes das diversas cotidianidades que habitam territórios turísticos. A ideia é atrever-se a cruzar até o caminho oposto e olhar como se ve desde a outra costa, desde quem vive nos territórios que visitamos como turistas e que cegamente não vemos, ou não queremos ver, em nossa avidez míope por férias. Isto requer compreender o Turismo de Base Comunitaria não somente como uma nova maneira de fazer negócios, senão como um novo modo de aprender a ver, ser, fazer e estar (Henríquez, 2014, p.2).

O programa se propõe a acompanhar o território durante 10 (dez) anos; e hoje conta com uma cooperativa de TBC constituída em setembro de 2017. Fazem parte da cooperativa, 3 (três) comunidades Mapuche e uma rota consolidada de serviços turísticos. No total são 32 (trinta e duas) iniciativas de alojamento, alimentação, atividades e artesanato

atravessaria zonas sagradas do território para o povo Mapuche para este fim.

${ }^{1} \mathrm{O}$ comunicado público emitido pelos diferentes territórios mapuches em volta do Rukapillan e Peweñantu vem denunciando por exemplo, o projeto IIRSA, a perda da biodiversidade e cambio climático.

${ }^{12}$ Trawun é um nome de origem mapuche que significa "encontro". A proposta e primeiro projeto tem origem no Centro Transdisciplinario de Estudios Ambientales da Universidad Austral de Chile. 
em 8 (oito) territórios distribuídos em torno da zona pré-cordilheira e cordilheira da Región de los Ríos. Destas, 28 (vinte e oito) são iniciativas familiares e 4 (quatro) comunitárias. A rota se encontra em volta de 4 (quatro) lagos, e do vulcão Villarica ou Rukapillan. Entre os benefícios obtidos desta parceria consolidou-se uma proposta de autocertificação para o Turismo de Base Comunitária. O mapa "Ruta y Circuito Trawun" da Figura 1 destaca o território, a Rota de Turismo de Base Comunitária e as 28 (vinte e oito) iniciativas familiares.

A proposta de TBC apresentada vem sendo impulsada na relação de atores institucionais, como é o caso da Universidade, o poder público, e principalmente das comunidades e famílias que participam e no concreto, conformam o projeto de TBC. O projeto conta na sua trajetória com diversos fundos de financiamento público. Neste sentido, vemos sob o marco de discussão proposta no artigo, como o TBC representa em si uma confluência de atores, e também de sentidos de desenvolvimento. O sentido atribuído ao Bem Viver provém desde a reafirmação dos territórios que compõem a experiência de vida que é promovida para os visitantes. Assim, as lutas pelo território deixam de ser disputas e se transformam em conhecimento real, ou seja, em valor e significado por meio das relações de convivência e reciprocidade promovidas pelo TBC, na busca de uma transformação interna, de maneira com que esse reconhecimento seja também de Bem Viver, resultando na manutenção do modo de vida sustentado do território, bem como na sua administração e resguardo.

\section{Considerações finais}

Perceber o TBC como cruzamento entre eixo alternativo ao desenvolvimento, meio de reafirmação de modos de vida tradicional e modelo de gestão territorial, inseridas estas dinâmicas dentro de um modelo de mercado dominado por uma visão capitalista, permite desde nossa perspectiva reflexionar em alguns pontos.

Em primeiro lugar, o TBC ao se colocar como instrumento de planejamento necessariamente deve-se inserir numa estrutura politica-instrumental dominada pela visão mecânica do Capital. Isso quer dizer que necessariamente se estabelece uma relação de confluência, na qual são disputados significados situados em racionalidades e ontologias opostas. $\mathrm{O}$ vinculo do TBC como o Bem Viver ou Viver Bem, permite dar maior capacidade a este corpo teórico que entra nesta disputa de significado. Acredita-se que isto possa permitir que as estruturas de dominação possam ser subvertidas em um grau que permita valorizar o modo de vida tradicional. Outra lógica que se pode compreender no TBC constitui-se como ferramenta que permite a geração de trabalho e renda de comunidades a partir da conservação de seus ecossistemas ameaçados e vulneráveis.

Como segundo ponto, o importante na relação do TBC com o BV/VB é justamente a ancoragem no território onde são disputadas lógicas de desenvolvimento. Ou seja, o TBC pode se constituir como uma reposta ao vazio gerado na experiência progressista no marco do BV/VB discutida no artigo. Evita-se, nesse sentido, que se perca o sentido do $\mathrm{BV} / \mathrm{VB}$ nas diferentes escalas de reconhecimento e atuação política-institucional, ao tempo que permite que esta relação possa-se estabelecer. 


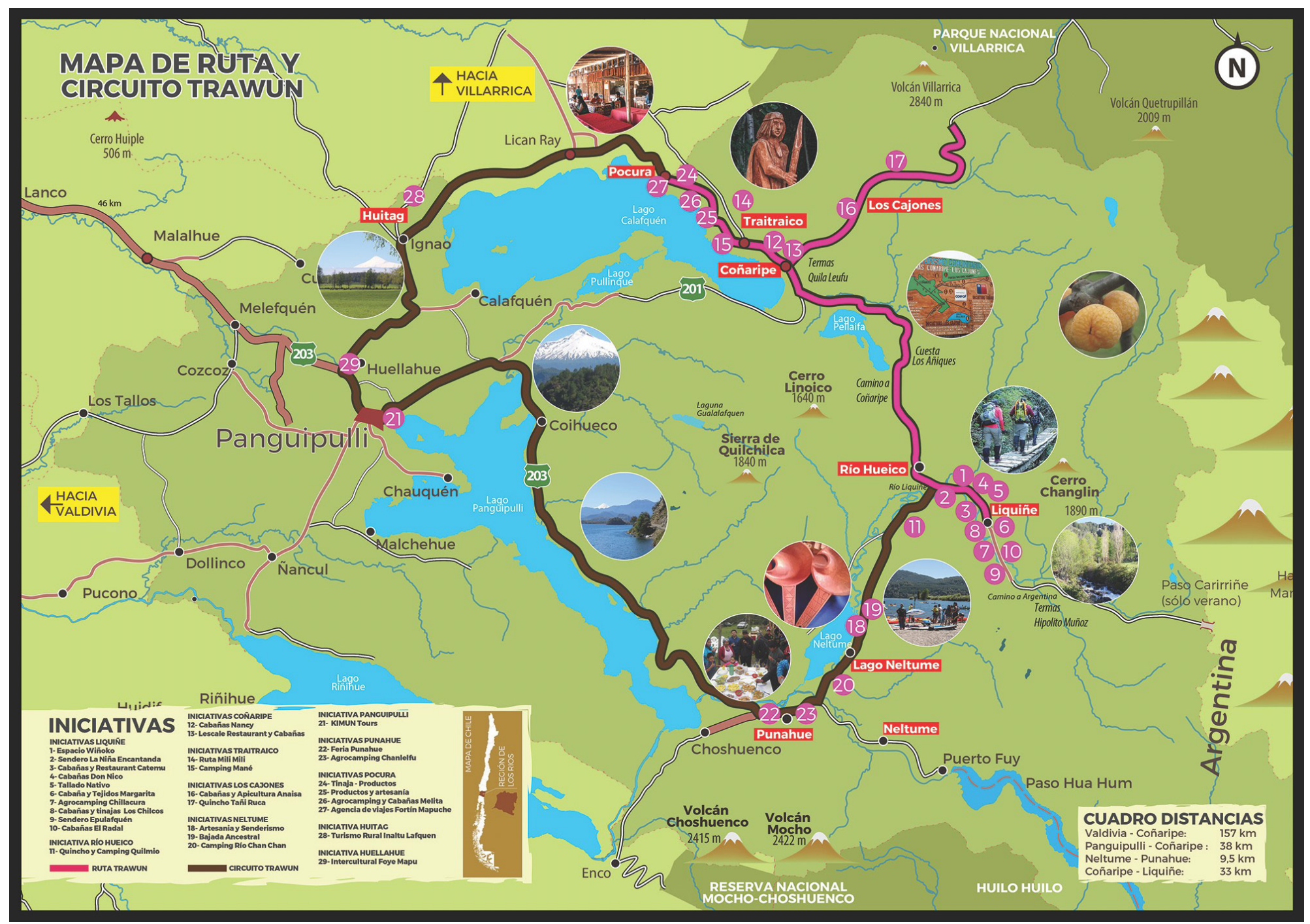

FIGURA 1 - Mapa de Ruta y Circuito Trawun, destacando o território, a Rota de Turismo de Base Comunitária e as 28 (vinte e oito) iniciativas familiares (Panguipulli, Sul do Chile). FONTE: Retirado do site de Trawun Cooperativa de Turismo de Base Comunitária (TRAWUN, 2019). 
A relação do TBC e BV/VB contribui e propõe num sentido amplo, um caminho de amadurecimento na trajetória do pensamento crítico Latino-americano, contribuindo na forma de uma práxis emancipadora que busca refletir as ontologias materiais. O reconhecimento do TBC como mecanismo de gestão do território que tem elementos chaves da Economia Social e Solidária, Ecossocioeconomia e Desenvolvimento à Escala Humana, mencionadas no artigo, permite de igual maneira, dar corpo a ação concreta e suporte às teorias assinaladas.

Assim, esse dialogo conjunto possibilita caminhar na disputa de geração de modelos alternativos ao desenvolvimento em territórios da Abya Yala onde atualmente existem tensões entre as comunidades indígenas e campesinas frente ao modelo extrativista que tenta abranger a totalidade de seu território ${ }^{13}$. Os povos que ainda ali vivem, vem sendo vítimas da redução de seus territórios e do assassinato de seus líderes. Esse avanço do modelo vigente segue sustentado no pensamento moderno/colonial, racional/positivista e capitalista/ neoliberal que vê tanto a natureza como também as pessoas como objetos funcionais de seus interesses de alcançar um desenvolvimento que se baseia na destruição, despojo e acumulação de riquezas.

Perante a aparente falta de novos horizontes emancipatórios, talvez se possa por meio de uma articulação concreta, entre dimensões econômicas e ontológicas que mantenham e promovam tanto modos de vida tradicionais como sua reafirmação sociocultural, uma ruptura significativa no imaginário moderno/colonial de desenvolvimento linear, para, como nos incentiva Solón (2016, p. 27), chegar a superar o conceito dos seres humanos como "produtores", "conquistadores" e "transformadores" da natureza, para enfim poder substituí-los pelo de "cuidadores", "cultivadores" e "mediadores" da natureza.

No diálogo conjunto entre Bem Viver e Turismo de Base Comunitária como teorias ligadas aos modos de vida e a práxis coletiva que as sustenta, propõe-se contribuir nesta nova perspectiva, buscando polinizar novas alternativas para a construção conjunta de um pensamento Econômico que surja desde e com a Terra.

\section{Referências}

Acosta, A. Conversatorio Buen vivir, Sumak kawsay: una oportunidad para imaginar otros mundos. Quito: Universidad Simon Bolivar, 2015.

Alcântara, L. C. S.; Sampaio, C. A. C. Bem Viver como paradigma de desenvolvimento: utopia ou alternativa possível? Desenvolvimento e Meio Ambiente, 40, 231-251, 2017. doi: 10.5380/dma.v40i0.48566

Cabanilla, E. Turismo Comunitario, su complejidad y aporte al Buen Vivir. Construcción de políticas públicas en base a modelo complejo de desarrollo territorial. In: Anais do Primer encuentro internacional de Turismo Comunitario y Social de la UNASUR. La Paz, Bolivia, 7-8 out. 2014, p. 01-06.

Coraggio, J. L. Las tres corrientes vigentes de pensamiento y acción dentro del campo de la Economía Social y Solidaria (ESS). Revista Brasileira de Estudos Urbanos e Regionais, 15(2), 11-24, 2013. doi: 10.22296/2317-1529.2013v15n2p11

Coriolano, L. N. De Arreglos Productivos Locales a Arre-

\footnotetext{
${ }^{13} \mathrm{O}$ projeto IIRSA constitui-se numa ameaça para os povos e comunidades do Abya Yala, pois: “em lugar de ser orientados pelos princípios de desenvolvimento sustentável é fonte de conflitos eco-sociopolíticos das comunidades em favor dos interesses políticos nacionais e econômicos que respondem a uma demanda de mercado internacional socialmente excludente" (De Lisio, 2013, p. 2).
} 
glos Productivos de Base Comunitaria. Gestión Turistica, 25, 8-41, 2016.

Cuevas V. R. Del Buen Vivir a la metrópolis latinoamericana: una aproximación a su sentido urbano. RELACult - Revista Latino-Americana de Estudos em Cultura e Sociedade. 3, ed. especial, 1-16, 2017

Cuevas V. R; Henríquez, C. Buen Vivir y Turismo de Base Comunitaria: Diálogo, posibilidades y perspectivas desde la economía Solidaria. Experiencia de la Ruta de turismo comunitario Trawun. In: Anais do XIII Seminário Internacional PROCOAS. USP, São Paulo, 9-11 out.2017.

Dagnino, E. Confluência perversa, deslocamentos de sentido, crise discursiva. In: Grimson, A. (Coord.). La cultura en las crisis latinoamericanas. Buenos Aires, Argentina: CLACSO, Consejo Latinoamericano de Ciencias Sociales, 2004. p. 195-216.

De Lisio, A. La IIRSA o la integración física suramericana como dilema eco-sociopolítico. Buenos Aires: CLACSO, 2013.

Del Popolo, F. (Ed.). Los pueblos indigenas en América (Abya Yala): desafíos para la igualdad en la diversidad. Libros de la CEPAL, N 151 (LC/PUB.2017/26). Santiago: CEPAL, 2017.

Escobar, A. Desde abajo, por la izquierda y con la Tierra: La diferencia de abya Yala/Afro/Latino- América. In: Celiberti, L.; Escobar, A. (Coords.). Rescatar la esperanza. Más allá del neoliberalismo y el progresismo. Barcelona: Entrepueblos, 2016. p. 337-369.

Fernandez, M.; Henríquez, C. Turismo de base comunitaria y redes a escala humana: principios para pensar una autocertificación para el turismo indígena. Guaju - Revista Brasileira de Desenvolvimento Territorial Sustentável, 4(1), 62-74, 2018.

Fernández-Comino, M. Turismo, Autodependencia y Redes a Escala Humana en la ruta Trawun, Región de los Ríos, sur de Chile. Valvívia, Chile, Tésis (Facultad de Ciencias Económicas y Administrativas MEDEH). Universidad Austral de Chile, 2018.

Global Witness, 2016. Disponível em: <https://www. globalwitness.org/en/campaigns/environmental-activists/ defender-la-tierra/>. Acesso em: mar. 2019.

Global Witness, 2017. Disponível em: <https://www. globalwitness.org/en/blog/nueva-informaci\%C3\%B3n-revela-que-197-personas-defensoras-de-la-tierra-y-el-medio-ambiente-han-sido-asesinadas-en-2017/>. Acesso em: jun. 2019.

Gudynas, E.; Acosta, A. El buen vivir o la disolución de la idea de progreso. In: Rojas, M. (Coord.). La medición del progreso y del bienestar. Propuestas desde América Latina. México DF: Foro Consultivo Científico y Tecnológico, 2011, p. 103-110.

Henríquez, C. Turismo de base comunitaria y avistamiento de flora y fauna marina, una propuesta de ecodesarrollo ambientalmente correcta, socialmente más justa y económicamente viable. Valdívia, Chile, TCC (Administración de Empresas Turísticas). Universidad Austral de Chile, 2007.

Henríquez, C. A construção participativa de indicadores territoriais socioambientais para o desenvolvimento regional sustentável. Análise propositiva para as comunidades do Rio Sagrado, Morretes (PR): Zona de Educação para o Ecodesenvolvimento. Blumenau, Dissertação (Desenvolvimento Regional). Universidade Regional de Blumenau - FURB, 2009.

Henríquez, C. Aproximaciones al turismo de base comunitaria en Chile. In: Anais do IX Congresso Internacional sobre Turismo Rural e Desenvolvimento Sustentável CITURDES. Universidade de São Paulo, 9-12 set. 2014.

Henríquez, C.; Zechner, T.; Sampaio, C. Turismo y sus Interacciones en las Transformaciones del Espacio Rural. Revista Ciencias Sociales, 18, 21-31, 2010.

Henríquez, C.; Pacheco, G. (Eds.).TRAWUN. Cooperativa de Turismo de Base Comunitaria Trawun 2.0. Guía de campo. Trawun. Valdivia: 2017.

Kuhn, T. A estrutura das revoluções científicas. São Paulo: Perspectiva, 1970.

Le Quang, M. El sentido político de la Iniciativa Yasuní-ITT: disputa entre capitalismo verde y ecosocialismo. Theomai, 32, 75-94, 2015.

Leff, E. Epistemologia ambiental. São Paulo: Cortez, 2001. 
Macas, L. El Sumak Kawsay. In: Hidalgo, C. L; Guillen, G. A.; Deleg, G. N. (Ed.). Antología del pensamiento indigenista ecuatoriano sobre Sumak Kawsay. Centro de Investigación en Migraciones CIM. Huelva, España: Pydlos, 2014. p. 179-192.

Mardones C. P.; Fernández D. F. Cinco siglos resistiendo: la marcha del 12 de octubre en Buenos Aires y Santiago de Chile como memoria colectiva cronotrópica y de reivindicación amerindia en Abya Yala. Si Somos Americanos. Revista de Estudios Transfronterizos, XVI (2), 143-171, 2016. doi: 10.4067/S0719-09482016000200006

Marín-Herrera, M. R-existencia de comunidades mapuche en el Parque Nacional Villarica. Aportes del desarrollo a escala humana para la justicia ambiental. Valdívia, Tesis (Facultad de Ciencias Económicas y Administrativas MEDEH). Universidad Austral de Chile, 2015.

Marín-Herrera, M.; Henríquez, C. Turismo de Base Comunitaria frente a conflictos etno-políticos y socio-ambientales en comunidades Mapuche del sur de Chile. In: Pinol Bazzi, A. (Ed.). Democracia versus Neoliberalismo. 25 años de neoliberalismo en Chile. Santiago de Chile: LOM, 2015. p. 304-325.

Max-Neef, M. Economía Herética: 35 años a contracorriente. Barcelona: Icaria editora. 2017.

Max-Neef, M.; Azkarraga, J.; Fuders, F.; Altuna, L. La evolución sostenible II. Eskoriatza: mondragon unibertsitatea, 2011.

Max-Neef, M.; Elizalde, A.; Hopenhayn, M. Desarrollo a Escala Humana: Conceptos, aplicaciones y algunas reflexiones. Montevideo: Nordan Comunidad, 1993.

Max-Neef, M.; Smith, P. B. La economía desenmascarada. Del poder y la codicia a la compasión y el bien común. Barcelona: Icaria, 2014.

Ortiz, R. H. Economía solidaria y pueblos indígenas: Desafíos para el buen vivir en la región. In: Lianza, S.; Chedid, H. F. (Orgs.). A economía solidária na América Latina: realidades nacionais e políticas públicas. Rio de Janeiro: Pró Reitoria de Extensão UFRJ, 2012. p. 87-98.

Pilquiman, M.; Henríquez, C. Aproximaciones al Turismo comunitario en Chile. In: O turismo rural comunitario como estratégia de desenvolvimento. Toledo Solha, K.; Elesbão, I.; Souza, M de. (Orgs.). Porto Alegre: Ed. da UFRGS, 2017. p. 135-151.

Porto-Gonçalves, C. W. De saberes y de territorios: diversidad y emancipación a partir de la experiencia latino-americana. Polis. Revista de la Universidad Bolivariana, 8(22), 121-136, 2009.

Quental, P. de A. Conflictos sociales, territorio, integración regional. IIRSA - Iniciativa para la Integración de la Infraestructura Regional Suramericana. América Latina. Buenos Aires: Biblioteca CLACSO, 2013.

Sampaio, C. A. C. Turismo como Fenômeno Humano. Princípios para se pensar a socieconomia. Rio Grande do Sul: EDUNISC, 2005.

Sampaio, C. A. C. Gestão que privilegia uma outra economia: ecossocioeconomia das organizações. Blumenau: Edifurb, 2010.

Sampaio, C. A. C.; Flores, 1. M; Rezende, A. J; Oyarzún, M. E. Perspectiva do Turismo Comunitário, Solidário e Sustentável. In: Sampaio, C. A. C.; Henríquez, C.; Mansur, C. (Orgs.). Turismo Comunitário, Solidário e Sustentável. Da crítica às ideias e das ideias à prática. Blumenau: Edifurb, 2011.

Sampaio, C. A. C.; Parks, C. D.; Mantovaneli Junior, O.; Quinlan, R. J.; Alcântara, L. C. S. Good living for the next generation: between subjectivity and common good from the perspective of eco-socio-economy. Saude e Sociedade, 26(1), 40-50, 2017.

Santos, B. S. Descolonizar el saber, reinventar el poder. Montevideo, Uruguay: Ediciones Trilce; Universidad de la Republica, 2010.

Skewes, J. C.; Henríquez, C.; Pilquimán, M. Turismo comunitario o de base comunitaria: una experiencia alternativa de hospitalidad vivida en el mundo mapuche. Tralcao Sur de Chile. Cultur. Revista de cultura y turismo, 6(2), 73-85, 2012.

Solón, P.¿Es posible Vivir Bien?. La Paz, Bolivia: Fundación Solón, 2016.

Souza, M. L de. O território: sobre espaço e poder, autonomia e desenvolvimento. In: Castro, I. E.; Gomes, P. C. C.; 
Correa, R. L. (Orgs.). Geografia: conceitos e temas. Rio de Janeiro: Bertrand Brasil, 2007.

Svampa, M. Pensar e desarrollo desde América Latina. In: Anais do Seminario Latinoamericano Derechos de la Naturaleza y Alternativas al extractivismo. Buenos Aires: 10-11 nov. 2011, p. 1-25. Disponível em: <http://www. maristellasvampa.net/archivos/ensayo56.pdf > Acesso em: jul. 2019.

Svampa, M. Frontera, D. Revista digital. Entrevista. Maristella Svampa y la crisis del ciclo progresista en Latinoamérica, 2016. Disponível em: <http://www.fronterad. $\mathrm{com} / \mathrm{q}=$ =maristella-svampa-y-crisis-ciclo-progresista-en-latinoamerica>. Acesso em: mar. 2019.

Tamburini, L. Territorio, libre determinación y autonomía indígena en el TIPNIS. Cuestión Agraria, 4, 39-45, 2018.

TRAWUN - Cooperativa de Turismo de Base Comunitária. Mapas. Disponível em: <https://www.trawun.cl/mapas/>. Acesso em: 20 jul. 2019.

Vanhulst, J. El laberinto de los discursos del Buen Vivir: entre el Sumak Kawsay y el socialismo del siglo XXI. Polis, revista Latinoamericana. 40, 233-261, 2015. Disponível em: https://polis.revues.org/10727
Walsh, C. Interculturalidad, conocimientos y decolonialidad. Signo y pensamiento, XXIV(46), 39-50, 2005. Disponível em: http://www.redalyc.org/articulo.oa? $\mathrm{id}=86012245004$

Walsh. C. Pedagogías decoloniais: práticas insurgentes de resistir, (re)existir e (re)vivir. Tomo I. Série Pensamiento decolonial. Ecuador: Abya-Yala, 2017.

WWF - World Wide Fund for Nature. Living Planet Report 2018: aiming higher. Gland, Suiça: WWF, 2018. Disponível em: <https://wwf.panda.org/knowledge_hub/all_publications/living_planet_report_2018/>. Acesso em: mar. 2020.

Zechner, T. C.; Henríquez, C.; Sampaio, C. A. C. Pensando o conceito de turismo comunitário a partir de experiências brasileiras, chilenas e costarriquenhas. In: Anais do II Seminário Internacional de Turismo Sustentável. Fortaleza, 12-15 mai. 2008.

Zibechi, R. El pensamiento crítico en la hora del colapso sistémico. In: Celiberti, L.; Escobar, A. (Coord.). Rescatar la esperanza. Más allá del neoliberalismo y el progresismo. Barcelona: Entrepueblos, 2016. p. 287-310. 